\title{
Postoperative Analgesia in Pediatric after below Umbilicus Surgery
}

E.F.Makram, I.E.Mostafa and I.M.AbdElfattah

Anesthesiology and Intensive Care Dept., Faculty of Medicine, Benha Univ., Benha, Egypt

E-Mail:Ismailed85@gmail.com

\begin{abstract}
Acute pain is one of the most common adverse stimuli experienced by pediatric population as a result of surgery. Children continue to experience moderate to severe unrelieved pain postoperatively despite the evidence to guide practice being readily available. Although the spectrum of options for effective perioperative pain management in children ranges from simple oral medication to invasive epidural, it is sad to observe that there is a wide incongruity between available technology and clinical practice. Pain is a complex phenomenon that is not well understood. There are several misconceptions relating to the physiology of pain in children. Pain should be assessed regularly to detect for the presence of pain and to evaluate the effectiveness of treatments. There need aid An number from claiming non-drug systems that might a chance to be used to mitigate children's torment. Social insurance professionals, need on assess their ache oversaw economy hones Concerning illustration a few investigations bring suggester non-drug routines would not routinely utilized. In this audit article we will examine the postoperative ache clinched alongside pediatric, routines about evaluation from claiming agony for pediatric and assess those part of ultrasonography done administration of torment.
\end{abstract}

Keywords: Postoperative, Analgesia, pediatric, Umbilicus surgery.

\section{Introduction}

Intense agony may be a standout amongst those A large portion basic unfriendly jolts encountered Toward pediatric populace Concerning illustration an aftereffect about surgery. Ache may be connected with expanded anxiety, avoidance, physical symptoms, Also expanded guardian trouble Also might prompt long haul impacts [1].

Notwithstanding the extent for these effects, the intense torment need around a tyke may be frequently all the deficiently evaluated and approached. Various myths, insufflate information "around caregivers, and insufficient requisition for learning help the absence of powerful management. Dread of unfriendly responses Also dangerous impacts regularly helped the insufficient utilization of analgesics [2]. The global companionship to those ponder from claiming agony need characterized agony as "an upsetting tactile and passionate background connected with real or possibility tissue harm or portrayed As far as such harm [3].

A few masters recommend that those neonate's statement from claiming ache doesn't fit inside the strict meaning of the global companionship to ponder about torment due to the prerequisite for self-report. This absence of capability with report card ache contributes of the disappointment to remember and treat ache forceful Throughout outset and early youth [3]. A result neonates can't verbalize their pain, they rely on upon others on recognize, assess, Furthermore oversee their torment. Therefore, human services tprofessionals could diagnose neonatal agony best by distinguishing the neonate's connected behavioral Also physiological reactions.

An expansive scale review news person that $40 \%$ for pediatric surgical patients encountered direct or extreme postoperative ache Furthermore that $75 \%$ needed insufflate absense of pain [4]. Those structural segments vital to recognize agony are officially exhibit during around 25 weeks gestation while the endogenous plunging inhibitory pathways need aid not completely produced until mid-infancy [5].

Opioid What's more different receptors need aid a significant part a greater amount generally dispersed over fetuses Also neonates [6]. Fetuses subjected to intrauterine trade transfusion with needle trans-hepatic entry will indicate both behavioral indications for agony and also a hormonal stress reaction [7]. Noteworthy torment incitement without fitting analgesia, for instance Throughout circumcision, won't just reason unsuitable ache during the period of the mediation as well as produces An 'pain memory' as illustrated by an overstated agony reaction will immunization Concerning illustration long Concerning illustration six months accompanying the circumcise [8]. Both neonates What's more babies have the ability with mount An graded hormonal stress light of surgical intercession Furthermore sufficient intra- and postoperative absense of pain won't best change the anxiety reaction Anyhow need Additionally been demonstrated to decrease horribleness and mortal sin [9].

This examine meant on Abstain from postoperative agony Previously, pediatric, figure it out routines for appraisal about 
torment for pediatric What's more assess the part of ultrasonography clinched alongside oversaw economy of agony.

\section{Subject and methods}

This is a review article, The search was performed in MEDLINE, Embase, Pubmed and CINAHL Plus in the same date range with the following mediacl terms: "Postoperative; Analgesia; pediatric; Umbilicus surgery",including articles from 2000 to 2019, Excluded articles from review are those of langauge other than English.

\section{Results}

Anatomy and Physiology of Pain

- Pain is a complex phenomenon that is not well understood. There are several misconceptions relating to the physiology of pain in children.

- Pain can be classified as nociceptive or neuropathic.

- Nociception is a normal response to both painful and tissue damaging stimuli.

- There are four stages involved in perceiving nociceptive pain: transduction, transmission, perception and modulation.

- Several theories have attempted to explain the subjectivity of pain. The gate control pain theory is accepted as providing the best explanation.

- An individual's perception of pain can be modified by several factors that cause the gate to open or close.

\section{Pharmacology of Analgesic Drugs}

- Many analgesic drugs have not been tested in children or are administered off-label.

- Misconceptions about analgesic drugs, particularly opioids, contribute to the undertreatment of pain in children.

- Confusion about opioid terminology leads to anxiety in families and healthcare professionals and suboptimal pain management practice.

- Combining analgesic drugs with non-drug strategies ensures better pain management outcomes.

- Nurses need to be aware of the hepatic and renal function of their patients and the need for reduced doses of analgesic drugs if these are impaired.

- The route of drug administration affects the onset and efficacy of a drug. There area range of advantages and disadvantages for children with different administration routes, which should be considered prior to analgesic selection.

- Analgesic drugs should be selected using a stepwise approach based on the type and severity of pain, onset and peak effect of the drug, benefits, risks and adverse effects.

- The main analgesic drugs fall into three categories: non-opioids, opioids and adjuvant analgesic drugs.

- Improved knowledge about pharmacology should enable nurses to make better decisions about appropriate selection of analgesic drugs, increase awareness of the impact and management of adverse effects, and improve individual nurses' ability to advocate for better analgesic prescribing.

\section{Pain Assessment}

- Pain assessment is vital for effective pain management.

- The first step in assessing pain is recording a pain history.

- The second step in pain assessment is assessing the child's pain using a developmentally appropriate pain assessment tool.

- The third step is evaluating the effectiveness of the pain-relieving interventions implemented.

- Validated and reliable pain assessment tools are available for children of all ages.

- The child's self-report of pain is considered the gold standard.

- Physiological, behavioural and self-report indicators can all be used to assess children's pain.

- Pain should be assessed regularly to detect for the presence of pain and to evaluate the effectiveness of treatments.

- Documentation of pain facilitates regular reassessment of pain and follow-up.

\section{Non-pharmacological Methods of Pain Relief}

- There are a number of non-drug methods that can be used to relieve children's pain.

- There are non-drug methods that can be used specifically to relieve infants' pain.

- Several of the non-drug methods can be used relatively easily in practice; others require special training.

- Many of the studies exploring the effectiveness of these non-drug methods have small samples and in some cases the results are inconsistent. Further research is needed.

- Nurses, and other healthcare professionals, need to evaluate their pain management practices as several studies have suggested non-drug methods are not routinely used.

\section{Discussion}

Youngsters keep on going with experience moderate with extreme unrelieved agony 
postoperatively [10], in spite of the confirmation on aide act constantly promptly accessible.

A pragmatic, useful methodology with pediatric postoperative agony management need been created what's more utilized in late A long time to mossycup oak pediatric centres. Reasonable plans are on distinguish torment to children, on minimize moderate and serious torment securely altogether children, on forestall torment the place it may be predictable, to bring ache quickly under control What's more will proceed ache control following release starting with healing center [11].

Aversion from claiming torment At whatever point possible, utilizing multi-modal analgesia, need been demonstrated will worth of effort great for almost constantly on situations and camwood a chance to be adjusted to day cases, major cases, those critically sick child, alternately the verwoerd adolescent. A lot of people intense agony benefits utilization strategies about simultaneous alternately co-analgesia dependent upon four classes about analgesics, in particular nearby anaesthetics, opioids, non-steroidal mitigating medications (NSAIDs), What's more acetaminophen (paracetamol). [12] Previously, particular, An local/regional pain relieving technobabble ought further bolstering be utilized within at cases unless there will be a particular reason not will and the opioid-sparing impacts of nearby anaesthetics, NSAIDs, and acetaminophen (paracetamol) would handy. Indeed, to large portions day-case procedures, opioids might be omitted On account combinations of the different three classes give acceptable great ache control By and large [13]. Local anesthesia will be About generally directed On anesthetized children, Be that as A percentage high hazard neonates have easier perioperative horribleness after inguinal surgery when up and about spinal anesthesia will be utilized [14].

An individualized agony administration want could a chance to be committed to each tyke In light of An cycle of evaluation and documentation of the child's ache utilizing suitable devices Also self-reporting, with intercessions joined of the appraisals [15]. An wellbeing net will be necessary for fast control of leap forward pain, to screen the viability about analgesia, will recognizing What's more treat unfriendly effects,
Furthermore to guarantee gear may be working effectively [16].

An extensive prospective 1-yr study from claiming more than 24000 pediatric territorial soporific pieces discovered an Generally speaking frequency for difficulties from claiming 0.9 clinched alongside 1000 blocks, with no difficulties about fringe systems. Difficulties were transient and A large portion were judged should need been brought about Toward the utilization of improper gear. [17] the commonest issues for pediatric local anesthesia need aid technical: whichever disappointment to make An piece or disappointment for upkeep of the square. Infection, weight zone problems, fringe nerve injury, nearby sedative toxicity, Furthermore genuine unfriendly impacts of opioids need aid a great part rarer, an extensive 5-yr prospective review for 10000 pediatric epidural catheter systems may be presently occurring in the uk on attempt to make those relative hazard from claiming these issues in advanced act. [14]. Ultrasonic permits ongoing visualization about anatomic structures, guides the blocking methodology itself, What's more indicates the spread of the nearby sedative result injected. An All the more fast onset about piece utilizing lesquerella nearby sedative result may be especially engaging to pediatrics the place A large portion pieces would sited to anesthetized patients. Ultrasonography direction could Additionally make supportive for caudal Also epidural obstructs for babies Also Youngsters Similarly as those sacrum What's more vertebrae are not completely hardened [18]. Ultrasound-guided strategies bring been portrayed for infraclavicular brachial plexus blockade, Furthermore lumbar plexus piece Previously, Youngsters [19].

Constant catheter strategies would turning into prevalent Previously, kids for femoral, brachial plexus, belt iliaca, lumbar plexus, Furthermore sciatic barricade. Disposable implantation units camwood a chance to be utilized as an elective will standard implantation gear. [20]. An expansive safety examine need made safedosing rules for racemic bupivacaine clinched alongside know youngsters Furthermore this need extraordinarily diminished those occurrence about systemic poisonous quality [11]. Racemic bupivacaine may be bit by bit constantly displaced Eventually Tom's perusing ropivacaine alternately 
levobupivacaine. This transform may be determined Eventually Tom's perusing those decreased possibility to systemic poisonous quality and the bring down danger about unwanted engine barricade. There would presently addition pediatric information should propose Possibly of the new operators [21].

Bosenberg need news person non-toxic plasma focuses about ropivacaine accompanying a dosage of up to $3 \mathrm{mg} \mathrm{kg-1}$ for ilioinguinal barricade [22], At $3.5 \mathrm{mg} \mathrm{kg}$ 1 for belt iliaca compartment barricade need been accounted for to foundation possibly dangerous plasma concentrations, in particular 4-5 mg ml-1 [23]. Thus, those diminished hazard for systemic poisonous quality ought not influence anaesthetists will surpass the past dosing rules for racemic bupivacaine. For nonstop epidural levobupivacaine, the utilization of a $0.0625 \%$ result gives the idea ideal to easier abdominal or urological surgery [24].

For solitary infusion caudal blockade, ropivacaine and levobupivacaine furnish comparable postoperative absense of pain contrasted with racemic bupivacaine for somewhat lesquerella early postoperative engine blockade, [4] and for no perceptible contrasts the middle of ropivacaine What's more levobupivacaine [25]. Those esterase frameworks in tissues, plasma, Also red platelets need aid full grown Previously, promptly life, Also ester nearby anaesthetics for example, amethocaine (tetracaine) Furthermore 2-chloroprocaine need aid especially appropriate Previously, neonates [26].

\section{Conclusion}

Moderate Furthermore extreme postoperative agony could Furthermore if be kept or regulated securely and adequately On the whole Youngsters whatever their age, seriousness about illness, or surgical methodology. Proceeding ache control at home following day-case surgery is key. The security about pain relieving treatment need progressed with the improvement of new medications Also more full understanding about their pharmacokinetics What's more Progress On neonates, babies and children, Also over ailment states. These developments bring been helped Toward specialized foul upgrades permitting additional exact conveyance from claiming absense of pain. The place mind boggling absense of pain may be needed, oversaw economy Eventually Tom's perusing a multidisciplinary intense torment less group with pediatric finesse will be those A large portion compelling approach.

\section{References}

[1] S. M. Walker, "Pain in children: recent advances and ongoing challenges," Br. J. Anaesth, Vol. 101(1), PP. 101-110, 2008.

[2] J. H. JF , "The assessment and management of acute pain in infants, children, and adolescents," Pediatrics, Vol. 108(3), PP. 793-797, 2001.

[3] J. A. Lemons, "Prevention and management of pain and stress in the neonate," Pediatrics, Vol. 105(2), PP. 454-461, 2000.

[4] P. A. Lönnqvist, G. Ivani, T. Moriarty, "Use of caudal-epidural opioids in children: still state of the art or the beginning of the end?," Pediatr. Anesth, Vol. 12(9), PP. 747-749, 2002.

[5] A. R. Wolf, "Effects of regional analgesia on stress responses to pediatric surgery," Pediatr. Anesth, Vol. 22(1), PP. 19-24, 2012.

[6] R. Nandi, D. Beacham, J. Middleton, M. Koltzenburg, R. F. Howard, and M. Fitzgerald, "The functional expression of mu opioid receptors on sensory neurons is developmentally regulated; morphine analgesia is less selective in the neonate," Pain, Vol. 111(1-2), PP. 38-50, 2004.

[7] C. V. Bellieni, "Pain assessment in human fetus and infants," AAPS J, Vol. 14(3), PP. 456-461, 2012.

[8] A. Taddio, J. Katz, A. L. Ilersich, G. Koren, "Effect of neonatal circumcision on pain response during subsequent routine vaccination," Lancet, Vol. 349(9052), PP. 599-603, 1997.

[9] A. Aynsley-Green, "Pain and stress in infancy and childhood-where to now?," Pediatr. Anesth, Vol. 6(3), PP. 167-172, 1996.

[10] T. Engelhardt, E. Steel, G. Johnston, and D. Y. Veitch, "Tramadol for pain relief in children undergoing tonsillectomy: a comparison with morphine," Pediatr. Anesth, Vol. 13(3), PP. 249-252, 2003.

[11]S. T. Verghese and R. S. Hannallah, "Acute pain management in children," J. Pain Res, Vol. 3, PP. 105-113, 2010.

[12] C. Greco, "Summary of the Pediatric Pain Management Symposium 2018 in Boston, MA," Pain Reports, Vol. 3(1),PP.13-20, 2018.

[13] M. Prabhu, P. Bortoletto, and B. T. Bateman, "Perioperative pain management 
strategies among women having reproductive surgeries," Fertil. Steril, Vol. 108(2), PP. 200-206, 2017.

[14]P.-A. Lönnqvist and N. S. Morton, "Postoperative analgesia in infants and children," Br. J. Anaesth, Vol. 95(1), PP. 59-68, 2005.

[15]A. M. Lynch-Jordan , “Applying quality improvement methods to implement a measurement system for chronic painrelated disability," J. Pediatr. Psychol, Vol. 35(1), PP. 32-41, 2010.

[16]N. Kumar, "WHO normative guidelines on pain management," Geneva World Heal. Organ, Vol. 2007, PP. 3-4, 2007.

[17]D. Dillane and B. T. Finucane, "Local anesthetic systemic toxicity," Can. J. Anesth. Can. d'anesthésie, Vol. 57(4), PP. 368-380, 2010.

[18]B. D. Sites , J. G. Antonakakis, "Ultrasound guidance in regional anesthesia: state of the art review through challenging clinical scenarios," Local Reg. Anesth, Vol. 2, PP. 1-9, 2009.

[19]M. B. Delvi, "Ultrasound-guided peripheral and truncal blocks in pediatric patients," Saudi J. Anaesth, Vol. 5(2), p. 208, 2011.

[20] J. Aguirre, A. Del Moral, I. Cobo, A. Borgeat, and S. Blumenthal, "The role of continuous peripheral nerve blocks," Anesthesiol. Res. Pract, Vol. 2012(3), PP. 35-39, 2012.
[21]D. Kaur and S. Anand, "Comparison between caudal bupivacaine and bupivacaine with ketamine for postoperative analgesia in children: A prospective randomized clinical study," Anesth. essays Res, Vol. 10(3), PP. 488495, 2016.

[22]A. Bösenberg, "Pediatric regional anesthesia update," Pediatr. Anesth, Vol. 14(5), PP. 398-402, 2004.

[23] O. Paut , "High plasma ropivacaine concentrations after fascia iliaca compartment block in children," Br. J. Anaesth, Vol. 92(3), PP. 416-418, 2004.

[24] J. Lerman , "Efficacy, safety, and pharmacokinetics of levobupivacaine with and without fentanyl after continuous epidural infusion in children: a multicenter trial.," Anesthesiology, Vol. 99(5), PP. 1166-1174, 2003.

[25] G. Ivani , "Caudal anesthesia for minor pediatric surgery: a prospective randomized comparison of ropivacaine $0.2 \%$ vs levobupivacaine $0.2 \%$," Pediatr. Anesth, Vol. 15(6), PP. 491-494, 2005.

[26] C. P. Long, D. F. McCafferty, N. M. Sittlington, H. L. Halliday, A. D. Woolfson, D. S. Jones, "Randomized trial of novel tetracaine patch to provide local anaesthesia in neonates undergoing venepuncture," Br. J. Anaesth, Vol. 91(4), PP. 514-518, 2003. 